
intervention to the risk profile http://ow.ly/iUok300hb8V

Sylvia Hartl ${ }^{1,2}$ and Jose Luis Lopez-Campos ${ }^{3,4}$

${ }^{1}$ Ludwig Boltzmann Institute of COPD and Respiratory Epidemiology, Vienna, Austria. ${ }^{2}$ Dept. of Resp. and Crit. Care, Otto Wagner Hospital, Vienna, Austria. ${ }^{3}$ Unidad Médico-Quirúrgica de Enfermedades Respiratorias, Hospital Universitario Virgen del Rocío, Seville, Spain. ${ }^{4}$ CIBER de Enfermedades Respiratorias (CIBERES), Madrid, Spain.

Correspondence: Sylvia Hartl, Ludwig Boltzmann Institute of COPD and Respiratory Epidemiology, Sanatoriumstreet 2, 1140 Vienna, Austria. E-mail: hartl.sylvia@aon.at

Received: May 032016 | Accepted: May 042016

Conflict of Interest: Disclosures can be found alongside the online version of this article at erj.ersjournals.com

\title{
References
}

1 Hurst JR, Donaldson GC, Quint JK, et al. Temporal clustering of exacerbations in chronic obstructive pulmonary disease. Am J Respir Crit Care Med 2009; 179: 369-374.

2 Roberts CM, Stone RA, Buckingham RJ, et al. Acidosis, non-invasive ventilation and mortality in hospitalised COPD exacerbations. Thorax 2011; 66: 43-48.

3 Groenewegen $\mathrm{KH}$, Schols AM, Wouters EF. Mortality and mortality-related factors after hospitalization for acute exacerbation of COPD. Chest 2003; 124: 459-467.

4 Elliott MW. Noninvasive ventilation in chronic ventilatory failure due to chronic obstructive pulmonary disease. Eur Respir J 2002; 20: 511-514.

5 Guerrero M, Crisafulli E, Liapikou A, et al. Readmission for acute exacerbation within 30 days of discharge is associated with a subsequent progressive increase in mortality risk in COPD patients: a long-term observational study. PLoS One 2016; 11: e0150737.

6 Brochard L, Isabey D, Piquet J, et al. Reversal of acute exacerbations of chronic obstructive lung disease by inspiratory assistance with a face mask. N Engl J Med 1990; 323: 1523-1530.

7 Needham DM. Mobilizing patients in the intensive care unit: improving neuromuscular weakness and physical function. JAMA 2008; 300: 1685-1690.

8 Roberts CM, Lopez-Campos JL, Pozo-Rodriguez F, et al. European hospital adherence to GOLD recommendations for chronic obstructive pulmonary disease (COPD) exacerbation admissions. Thorax 2013; 68: 1169-1171.

9 Kirschner M, Bauch A, Agusti A, et al. Implementing systems medicine within healthcare. Genome Med 2015; 7: 102 .

10 McCarthy C, Brennan JR, Brown L, et al. Use of a care bundle in the emergency department for acute exacerbations of chronic obstructive pulmonary disease: a feasibility study. Int J Chron Obstruct Pulmon Dis 2013; 8: 605-611.

\section{European idiopathic pulmonary fibrosis Patient Charter: a missed opportunity}

To the Editor:

The European charter for idiopathic pulmonary fibrosis is a welcome document [1], highlighting unmet needs in patients which will inform policy makers across Europe. However, it is sad that an important opportunity to involve children with interstitial lung diseases (ILDs) has been missed. There is a current pan-European paediatric ILD consortium [2] which could have been used to access these children and families. Our own work also highlighted similar themes [3]: diagnostic delay, the need for improved holistic care and written information, and also interestingly highlighted a previously undescribed issue, the high prevalence of feeding disorders in these children. So the European Charter, excellent as it is, sadly represents a lost opportunity to represent the needs of children with rare lung diseases to health commissioners.

@ERSpublications

Children with ILD should also have been included in the IPF European Charter http://ow.ly/ZBfA0

Andrew Bush ${ }^{1}$, Angelo Barbato ${ }^{2}$, Annick Clement ${ }^{3}$, Steve Cunningham ${ }^{4}$, Jacques de Blic $^{5}$, Carlee Gilbert ${ }^{6}$, Lutz Goldbeck ${ }^{7}$, Nural Kiper ${ }^{8}$, Nicolaus Schwerk ${ }^{9}$ and Matthias Griese ${ }^{10}$ 
${ }^{1}$ Respiratory Paediatrics, National Heart \& Lung Institute, Imperial College London, London, UK. ${ }^{2}$ Woman and Child Health, University of Padova, Padova, Italy. ${ }^{3}$ Pediatric Pulmunology, AP-HP Hôpital Trousseau, Paris, France. ${ }^{4}$ Dept of Respiratory and Sleep Medicine, Royal Hospital for Sick Children, Edinburgh, UK. ${ }^{5}$ Pneumologie Pédiatrique, Hôpital Necker Enfants Malades, Paris, France. ${ }^{6}$ UK chILD Foundation, Liverpool, UK. ${ }^{7}$ Child and Adolescent Psychiatry/ Psychotherapy, University Hospital Ulm, Ulm, Germany. ${ }^{8}$ Dept of Pediatric Pulmonology, Hacettepe University Faculty of Medicine, Ankara, Turkey. ${ }^{9}$ Pediatrics, Hannover Medical School, Hannover, Germany. ${ }^{10}$ Pneumology, University of Munich, Dr. von Haunersches Kinderspital, Munich, Germany.

Correspondence: Andrew Bush, Respiratory Paediatrics, National Heart \& Lung Institute, Imperial College London, Sydney Street, SW3 6NP, London, UK. E-mail: a.bush@imperial.ac.uk

Received: March 102016 | Accepted: March 132016

Support statement: Funding information for this article has been deposited with FundRef.

Conflict of interest: None declared.

\section{References}

1 Bonella F, Wijsenbeek M, Molina-Molina M, et al. European IPF Patient Charter: unmet needs and a call to action for healthcare policymakers. Eur Respir J 2016; 47: 597-606.

2 Bush A, Anthony G, Barbato A, et al. Research in progress: put the orphanage out of business. Thorax 2013; 68: 971-973.

3 Gilbert C, Bush A, Cunningham S. Childhood interstitial lung disease: family experiences. Pediatr Pulmonol 2015; 50: $1301-1303$.

Eur Respir J 2016; 48: 282-283 | DOI: 10.1183/13993003.00505-2016 | Copyright @ERS 2016

From the authors:

We would like to acknowledge the comments of A. Bush and colleagues on the European idiopathic pulmonary fibrosis (IPF) Patient Charter and seize the opportunity to provide additional information on this important initiative.

As described in table 2 of our article [1], the European IPF Patient Charter was an initiative driven by 11 established patient organisations active in the area of IPF, who approached the medical experts and healthcare professionals who authored the manuscript, to seek consensus on the key recommendations to be addressed to national and European policy-makers.

The patient organisations wanted to develop an advocacy tool on IPF with the intent of driving political action at both the European and national levels. IPF is one of the interstitial lung diseases (ILDs) that occur in adulthood [2], not in children, and is different to other types of lung fibrosis that could mimic IPF and could affect children (such as telomeropathies and familial pulmonary fibrosis). Hence, children and their families were not initially involved in this process.

Thanks to the work initiated with the European IPF Patient Charter, we are now laying the foundations for the setup of a European Reference Network on Rare Lung Diseases that will involve medical experts from different therapeutic areas to exchange best practices, and improve the diagnosis and treatment of patients with rare pulmonary diseases. We believe that the work conducted by the pan-European paediatric ILD consortium could bring an added value and we are therefore confident that a fruitful collaboration could be initiated within the framework of the European Reference Network.

It is our opinion that we could not have come to this important project without the European IPF Patient Charter. In a true spirit of collaboration, we hope that A. Bush and colleagues will agree that the European IPF Patient Charter paved the way for new and unexplored opportunities to improve care, and raise visibility of the needs of children and adults with rare lung diseases, which should be considered as an important success story rather than a missed opportunity.

@ERSpublications

The European IPF Charter paved the way to improve care and raise visibility of the needs of patients affected by ILD http://ow.ly/4nrVHV

Francesco Bonella ${ }^{1}$, Marlies Wijsenbeek ${ }^{2}$, Maria Molina-Molina ${ }^{3}$, Annette Duck ${ }^{4}$, Rosalba Mele ${ }^{5}$, Klaus Geissler ${ }^{6}$ and Wim Wuyts ${ }^{7}$

${ }^{1}$ Ruhrlandklinik, Westdeutsches Lungenzentrum am Universitätsklinikum Essen gGmBH, Essen, and European Respiratory Society, Diffuse Lung Parenchymal Disease (DLPD) Group (1.5) Secretary, Germany. ${ }^{2}$ Dept of Pulmonary Medicine, Erasmus Medical Centre, University Hospital, Rotterdam, The Netherlands. ${ }^{3}$ ILD Unit, Department of Respiratory Medicine, University Hospital of Bellvitge, Institut d’Investigacions Biomèdiques de Bellvitge, Barcelona, and 